\title{
Socioeconomic Status, Parental Involvement and Implications for Subjective Well-Being During the Global Pandemic of Covid-19
}

\author{
Ernesto Treviño ${ }^{1 \dagger}$, Catalina Miranda ${ }^{2 * \dagger}$, Macarena Hernández ${ }^{1 \dagger}$ and Cristóbal Villalobos ${ }^{2 \dagger}$ \\ ${ }^{1}$ Faculty of Education, Centro de Justicia Educacional (CJE), Pontificia Universidad Católica de Chile, Santiago, Chile, ${ }^{2}$ Centro de \\ Estudios de Políticas y Prácticas en Educación (CEPPE-UC), Pontificia Universidad Católica de Chile, Santiago, Chile
}

\section{OPEN ACCESS}

Edited by:

Pablo Rivera-Vargas,

University of Barcelona, Spain

Reviewed by:

SE Mol,

Leiden University, Netherlands Horacio Pedroza,

Universidad Autónoma de Baja

California, Mexico

Alejandra Cortazar,

Centro de Estudios de Primera

Infancia (CEPI), Chile

${ }^{*}$ Correspondence:

Catalina Miranda

ccmiranda@uc.cl

tThese authors have contributed equally to this work and share first authorship

Specialty section: This article was submitted to Educational Psychology, a section of the journal

Frontiers in Education

Received: 22 August 2021 Accepted: 13 October 2021 Published: 02 November 2021

Citation:

Treviño E, Miranda C, Hernández M and Villalobos C (2021) Socioeconomic Status, Parental Involvement and Implications for Subjective Well-Being During the Global Pandemic of Covid-19. Front. Educ. 6:762780. doi: 10.3389/feduc.2021.762780
School closures prompted by the global outbreak of COVID-19 have impacted children's subjective well-being. In this context, a growing number of studies has pointed out that the experience of learning at home is an essential factor influencing their subjective well-being, raising the importance of parental involvement in the educational process of their children. This article explores the formal and informal parental practices of home learning during school closures period in 19 countries and their explanatory factors, with the further aim of discussing their implications for children's subjective well-being. The study uses the International COVID-19 Impact on Parental Engagement Study (ICIPES) database and develops a regression analysis of family, child, and school factors predicting parental involvement in homeschooling. The main findings show that parents' socioeconomic status is a critical predictor of both formal and informal parental practices. In addition, the results denote the impact of other factors, such as the level of parental confidence with the use of technology and children's age and gender (in the case of informal activities). Based on these findings, the article discusses policy implications to promote parental involvement and children's subjective well-being.

\section{Keywords: socioeconomic status, parental involvement, school closure, COVID-19, subjective well-being}

\section{INTRODUCTION}

School closures during the expansion of the COVID-19 pandemic on education have impacted $94 \%$ of the world's student population (United Nations, 2020a). As a response to this scenario, $90 \%$ of the ministries of education have implemented some form of remote learning approaches, including radio, television, or the internet (UNICEF, 2021).

Research about the pandemic effects on children and adolescents is still emergent. Recent literature reviews have alerted about the impact of lockdown measures -and notably schools' closures-on children's well-being. Indeed, consistent evidence has shown not negligible effects on a range of emotional, behavioral, and restlessness/inattention problems, as well as a decrease in life satisfaction, which are expected to disproportionally affect disadvantaged students (Bathia, 2020; Rajmil et al., 2021; Viner et al., 2021). For example, evidence for children and adolescents aged 3-18 years in Italy and Spain states that $85,7 \%$ of parents perceived changes in their children's emotional status and behavior, including symptoms such as difficulty concentrating, boredom, irritability, feelings of loneliness, uneasiness, and worries (Bathia, 2020). Moreover, data from Oslo (Norway) has identified a significant decline in life satisfaction among boys and girls during the 
restriction period (Bathia, 2020), and in Canada more than half of the children 9-15 years surveyed presented changes that contribute to a lower level of subjective well-being (Mitra et al., 2021).

Several studies have pointed out that the experience of home learning is an essential factor influencing their subjective wellbeing. In this area, research has posited that the quantity and difficulty of school homework is a predictor of well-being, i.e., when the school work load is high and/or difficult it has been related with a decrease in subjective well-being during the pandemic (Engel de abreu et al., 2021). Moreover, research has highlighted the association between academic activities and socioemotional problems, showing that learning activities are negatively associated with behavioral problems (e.g., emotional symptoms, hyperactivity/inattention, and peer relationship problems) (Tso et al., 2020). In addition, a recent study shows that students with better learning experiences at home report lower emotional reactions (e.g., "felt sad," "felt angry," "felt lonely") and low somatic/cognitive responses (e.g., "had trouble concentrating," "had headaches") (Larsen et al., 2021). Considering these findings, international reports have called to enhance parental support of children's homeschool experiences to protect their subjective well-being, while advancing on research about families' involvement in learning at home (e.g., Engel de Abreu et al., 2021; O'Connor et al., 2020; OECD, 2020).

Different national studies developed in the context of the global pandemic have provided evidence about parents' responses to school closures (Zancajo, 2020). In general, the results show the critical role of parents' SES in supporting their children learning at home. In this sense, all the papers have shown how socioeconomic differences-measured as occupational status, educational level, or family income-are relevant factor predicting the quality of home support for schooling to face the COVID-19 pandemic in countries as diverse as Spain (Bonal and González, 2020), Chile (Treviño et al., 2021), England (Andrew et al., 2020; Bayrakdar and Guveli, 2020) and Netherlands (Bol, 2020). Most of these studies have been developed in middle and/or high-income countries through online surveys. In this way, while previous literature has provided initial evidence on the relationship between COVID19, parental support, and subjective well-being, studies have not yet examined global patterns in a wider range of countries, including OECD and non-OECD members. Therefore, expanding research to a cross-national sample of countries opens the opportunity to study global trends in this area in diverse geographical, socioeconomic and cultural settings.

Based on these emergent results and adopting a supranational perspective, this article explores the parental practices of homelearning during school closures period in 19 countries and its explanatory factors through regression models, with the aim of discussing its implications for the subjective well-being of children and adolescents. The study uses the International COVID-19 Impact on Parental Engagement Study (ICIPES) database (Osorio-Saez EM. et al., 2021), which includes data from countries as diverse as Chile, United States, Ghana, China, Japan or Pakistan.
The article is divided into four sections. The first part presents the research framework of the study, in which we delve into the concept of parental involvement and its explanatory factors, as well as its relationship with children's well-being. The second section describes the research method, including the data, variables and analytical strategy used. The third part presents the main findings. The paper ends with the core conclusions and a set of policy and research implications.

\section{RESEARCH FRAMEWORK}

The expansion of the covid-19 pandemic can be defined as a global socio-natural disaster. It is socio-natural because, in contrast to the epidemiological views of the pandemic, COVID-19 can be understood as a both natural and social phenomenon, dissolving the modernist dichotomy that divided humans from nature (Rogers et al., 2013). It is a disaster, since it has interrupted routines and has caused the collapse and/or stress of several social organizations and institutions (Lavell et al., 2020). Finally, it is global, not only because of the scale of the problem, but also because of the transnational and relational nature of its consequences (Castells, 2006).

This conceptualization of COVID-19 as a global socio-natural disaster reinforces the idea that all systems and organizations in the world have been challenged by the pandemic. In education, the outbreak of the COVID-19 pandemic has generated a global transformation rarely seen since the World War II. COVID-19 has forced schools to transform the learning process and to promote distance or online teaching. Additionally, students' daily interactions with their peers have been interrupted, generating a decrease in the opportunities of peer-to-peer socialization of children and adolescents. Finally, homes adapted to the new education dynamics, with parents assuming a more active role in the school teaching process while, in many cases, working from home. In this context, parental involvement in the educational process has emerged as one of the central topics of research due to school closures during the pandemic (Bonal and González, 2020).

Parental involvement is as the participation of parents in the educational process and experience of their children (Wilder, 2013). More precisely, parental involvement refers to the "proactive engagement of parents in various activities and behaviors that aim to promote learning and development of their children" (Ma et al., 2016: 773). Different studies have demonstrated the benefit of parental involvement on student achievement (e.g., Ma et al., 2016), social-emotional skills (Van Voorhis et al., 2013), well-being, and mental health (Hornby and Blackwell, 2018). Considering the vastness of the concept (Goodall, 2013), researchers have operationalized the term as a continuum between involvement in/with school, involvement in schooling, and involvement with learning of children and adolescents (Goodall and Montgomery, 2014). There are also diverse types of involvement such as parenting, communicating, volunteering, learning at home, decision making and collaborating with the community (Epstein, 2011), which can be either overt or implicit practices (Tan et al., 2020). Parental 
involvement can be analyzed according to spheres of involvement in which a difference has been introduced between practices at school and at home (Hornby and Blackwell, 2018). Focusing on the home sphere, the literature distinguishes formal and informal educational practices. Formal educational practices directly aim at supporting schooling-such as teaching or practicing their numeracy or literacy skills-while informal educational practices, indirectly or spontaneously, expose students to opportunities to learn, for example through cooking or playing games (Skwarchuk et al., 2014).

Research has positioned parental involvement as a critical condition to support student learning and well-being. Simultaneously, the evidence shows the weight of the SES in the capacity of parents to provide support for schooling, due to inequalities in the distribution of economic, social and cultural capitals among families (Harris and Goodall, 2008; Lareau, 2000, 2011; Tan et al., 2020). For example, a recent metanalysis found that parental education is related to the capacity to provide support, showing that parents with higher education can offer more home support to their children (Tan et al., 2020). Adopting a broader perspective, Horbny and Lafaele (2011) have raised attention to four types of factors of parental involvement for all SES groups: a) individual parent and family factors (e.g., parental beliefs and perceptions on involvement, current life contexts, class, ethnicity, and gender); b) child factors (e.g., age, learning difficulties, disabilities or talents, and behavioral problems); c) school factors (e.g., differing goals and agendas, attitudes, language used); and, d) societal factors (e.g., historical and demographic, political, economic) (Horbny and Lafaele, 2011). Consequently, parental involvement seems to be the product of particular social, economic, and cultural conditions, in which the SES is a relevant factor, but not the only explanatory variable. In terms of the specific role of SES on parental involvement, research has outlined that low-SES families face barriers in terms of economic hardships, time-consuming work, lower pedagogical competencies, and scarce interactions with schools and teachers (e.g., Lareau, 2000; Horby and Lafaele, 2011; Wang et al., 2016).

Different national studies have investigated families' responses to school closures, highlighting the critical role of parental SES on homeschooling practices (Zancajo, 2020). In this line, available evidence, proceeding primarily from OECD's countries -such as England, Spain, or the Netherlands-has shown inequalities in the number of hours dedicated to learning at home and the type of activities in relation to family income (Andrew et al., 2020). The literature has also found variations on involvement with more educated families providing both higher quality and more intense support (Bol, 2020; Bayrakdar and Guveli, 2020). Also, higher SES parents are more confident on their abilities to satisfy their children's learning needs (Bonal and Gonzalez, 2020; Bol, 2021). Finally, higher SES families tend to engage to a greater extent in informal homeschooling practices aligned to school logic as well as in extra-curricular activities (Bonal and Gonzalez 2020; Treviño et al., 2021).

Other family factors, along with SES, are also related to parental involvement. One study points out that single parents tend to spend significantly less time on schoolwork at home in comparison to bi-parental households during COVID-19 school closures (Bayrakdar and Guveli, 2020). This suggests that household composition (Myers and Myers, 2015) may be related to the burden that single parents may have faced during this period (Bayrakdar and Guveli, 2020). Complementarily, recent studies have discussed the trend of more significant support in primary school for boys and more intensive support for girls in secondary education (Bol, 2020). Finally, initial evidence shows that online learning is a factor that moderates the role of parents' SES in homeschooling (Bayrakdar et al., 2020).

The intensity of school activities during the pandemic also may affect well-being in the households. As the teaching processes moved from classrooms to the households, parents or adults in charge do not necessarily have the skills or time to support intense school activities and homework (Ponce et al., 2021). Therefore, during the pandemic, the level of pressure on parents to teach their children at home (FontenelleTereshchuk,2021; Parczewska, 2020) may create tension in the relationship and negatively affect subjective well-being of children and adolescents.

Recent evidence shows a positive association of parental engagement with facilitating conditions (e.g., the existence of tools and technological platforms provided or suggested by schools), as well as social influence (e.g., parents exposition and exchanges with other parents, teachers, children, etc). Finally, there is a negative relationship of parental engagement with the knowledge or performance when using technological devices (Osorio-Saez E. et al., 2021).

Summarizing, the literature shows that formal and informal parental involvement practices in home-learning are linked to children's subjective well-being. This study explores homelearning parental practices during school closures due to COVID-19 in 19 countries and the factors that explain such practices. Consistently with available research, the study examines how formal and informal educational practices at home are related to family factors (e.g., SES, confidence using technology), children's factors (e.g., age, gender), and school requirements for families when supporting home-learning.

\section{DATA AND METHODS}

\subsection{Data}

The data for this study comes from the International COVID-19 Impact on Parental Engagement Study (ICIPES) (Osorio-Saez EM. et al., 2021). This study "investigated the ways in which parents and caregivers are building capacity to engage with children's learning during the period of social distancing arising from the global Covid-19 pandemic" (Osorio-Saez et al., 2020:3). The survey was conducted online in 23 countries (Belgium, Cameroon, Chile, China-MainlandHongKong-Macao, Colombia, Costa Rica, El Salvador, Ethiopia, Ghana, Honduras, India, Italy, Japan, Mexico, Pakistan, Peru, Spain, Sri Lanka, Tanzania and Zanzibar, Turkey, United Kingdom, Uruguay, and United States), achieving a total sample of 4.658 parents/caregivers with children between 6 and 16 years old (mean $=4.36$ ). 
TABLE 1 | Number of observations and days the school was fully closed per country.

\begin{tabular}{lcc}
\hline Countries & N & Days: Fully closed \\
\hline Chile & 1.597 & 67 \\
China & 217 & 33 \\
Colombia & 94 & 115 \\
Costa Rica & 155 & 189 \\
El Salvador & 83 & 205 \\
Ethiopia & 171 & 151 \\
Ghana & 142 & 50 \\
Honduras & 246 & 147 \\
India & 54 & 146 \\
Italy & 517 & 66 \\
Japan & 159 & 11 \\
Mexico & 244 & 180 \\
Pakistan & 45 & 112 \\
Sri Lanka & 199 & 141 \\
Tanzania & 58 & 52 \\
Turkey & 78 & 129 \\
United Kingdom & 191 & 62 \\
United States & 289 & 0 \\
Uruguay & 61 & 20 \\
& &
\end{tabular}

Source: ICIPES, 2020 (Osorio-Saez EM. et al., 2021) and UNICEF, 2021. Note: The number of observations refers to the number of parents that completed the survey.

Despite having information for 23 countries, four were omitted from this study due to a low response rate. Therefore, the final sample is composed of 4.600 parents/caregivers belonging to 19 countries. As each country experienced school closures due to the COVID-19 pandemic at different periods, Table 1 presents the number of observations per country and the number of days schools were fully closed (between March 11, 2020-February 2, 2021), according to UNICEF (2021) data.

\subsection{Procedures}

Data collection took place from May 2020 to August 2020. The survey was distributed through the social networks of the participating academic institutions in each country (OsorioSaez, et al., 2021a). The survey was translated into seven languages (Japanese, Turkish, Spanish, Urdu, Traditional Chinese, French and Italian). In addition, a minimum threshold of 200 parents with complete surveys was established to ensure data quality ${ }^{1}$ (Osorio-Saez, et al., 2020). However, it is important to note that the sample is nonprobabilistic and not representative at the country level. In fact, most of the parents that answered the survey have a higher education degree, a figure that suggests that the sample may be biased towards higher SES households.

\subsection{Variables}

For the analysis, we constructed two parental involvement variables: formal educational practices and informal educational practices. Additionally, and considering our research framework, we use as predictors family SES,

${ }^{1}$ All the data are free and its available at doi: $10.1016 / \mathrm{j} . \mathrm{dib} .2021 .106813$. confidence using technology and family structure; as well as child age, gender, and rurality; and intensity of school activities and homework. Table 2 shows the descriptive statistics of the variables used in the analysis.

\subsubsection{Dependent Variable}

Based on a Confirmatory Factor Analysis (CFA), we measure parental involvement in two dimensions: formal educational practices and informal educational practices. On the one hand, the formal educational practices dimension was created using three items: i) Are you teaching your child at home? (Taking the time for sitting and explaining the topics and activities to them) (PEHS); ii) My children and I have a set homeschooling timetable (PE_4); and iii) Check the school's emails, blog, and website to follow the activities they suggest for the children (PUTR_1). The items involving formal educational practices have answer options in a form of Likert scale (Always, Often, Occasionally, Rarely, and Never). However, due to the upward bias of parental responses we dichotomized these variables assigning Yes $=1$ for the options Always, Often, and Occasionally, and recoding Rarely and Never as No $=1$. On other hand, the informal educational practices dimension was constructed through eight items: i) Eating meals together (PENTMA_1); ii) Shopping online (PETMA_3); iii) Learned about something on the internet (PETMA_4); iv) Reading an electronic book or article together (PETMA_5); v) Watching a film and discussing it together (PETMA_6); vi) Created a piece of art on paper or using any other physical material together (PENTMA_7); vii) Used technology to create or edit videos, photos or music or other content (PETMA_7); and, 8viii) Played computer/video games (PETMA_9). It is important to note that the items of informal educational practices are dichotomous, and they were collected as $1=$ Yes, and $0=$ No. In both scales, we constructed an index, with mean $=0$ and standard deviation $=1$.

The CFA is conducted using a theorical model on parental involvement following the research framework. In the formal educational practices dimension, three items available in the database related to learning support are selected. Meanwhile, in the informal educational practices, 17 actions performed at home that indirectly expose students to the acquisition of learning are identified. In this second dimension, an Exploratory Factor Analysis (EFA) was previously applied to determine the number of factors related to spontaneous activities in the home, the objective of this analysis was to establish the variables to be introduced in the CFA model. As a result of the EFA, we decided to include eight items that establish the unidimensional presence of the construct to measure. Finally, the CFA model has an acceptable statistical fit, according to Brown (2006) $=\chi^{2}(43)=$ 167.230, $p=0.00$, CFI $=0.943$, TLI $=0.927$, RMSEA $=$ 0.022 , SRMR $=0.031$ and a moderate correlation between the dimensions $(0,31)$.

The Kuder-Richardson Formula $20(\mathrm{KR}-20)$ is used to measure the reliability of each dimension, since the data set consist of dichotomous variable. Equation 1 shows the formula of the KR-20, where $k$ is the number of items, $p j$ is 
TABLE 2 | Descriptive statistics for all countries.

\begin{tabular}{|c|c|c|c|c|}
\hline Variable & Mean & Standard deviation & Minimum & Maximum \\
\hline Formal educational practices & 0 & 1 & -0.2005 & 0.0759 \\
\hline Informal educational practices & 0 & 1 & -1.0052 & 0.7776 \\
\hline Socioeconomic Status & 0 & 1 & -2.3512 & 4.0029 \\
\hline Technology at home & 0.9096 & 0.2868 & 0 & 1 \\
\hline Receives the learning plan & 0.8411 & 0.3656 & 0 & 1 \\
\hline Female & 0.4974 & 0.5000 & 0 & 1 \\
\hline Family structure: Raising a child without a partner & 0.1329 & 0.3394 & 0 & 1 \\
\hline Parental confident & 0.8424 & 0.3644 & 0 & 1 \\
\hline Children in the household & 1.3087 & 1.4491 & 0 & 10 \\
\hline Rural & 0.1670 & 0.3731 & 0 & 1 \\
\hline Child age & 4.3597 & 3.2573 & 0 & 11 \\
\hline
\end{tabular}

Source: ICIPES, 2020 (Osorio-Saez EM. et al., 2021). Note: For dummy variables the column mean represents the proportion of the cases in the category 1.

the proportion of correct responses to item $\mathrm{j}$ and $\sigma_{\mathrm{x}}^{2}$ is the variance of sum test scores (Foster, 2021)

$$
\frac{k}{k-1}\left(1-\frac{\sum_{j=1}^{k} p_{j}\left(1-p_{j}\right)}{\sigma_{x}^{2}}\right)
$$

The KR-20 score for the formal educational practices dimension is 0.28 and 0.63 for informal educational practices. The second dimension presents a value close to 0.7 (an acceptable consistency). While the first dimension presents low reliability, this is because more than half of the participants $(N=2,797)$ answered that they carried out the three formal educational practices, a situation that restricts the variance and has consequence in the low reliability. However, as both dimensions are theoretically relevant and the correlation between them indicates a difference between the practices performed by parents, we decided to interpret this result with caution and include this dimension (formal educational practices) in the analysis. Finally, it is worth mentioning that for the CFA model and the reliability estimation, the total sample $(N=4,600)$ is used.

\subsubsection{Independent Variable \\ 3.3.2.1 Family Factors}

To measure SES, we used the scale constructed by Osorio-Saez and colleagues (2021b, 2020), which shows robust fit and reliability indicators. The authors created this scale through CFA using four questions: Q5: What do you do in your main job? (e.g., teach high school students, help the cook prepare meals in a restaurant, manage a sales team), which was an open question that was recoded into an ordinal variable following the list of occupations described in the one-digit ISCO (International Standard Classification of Occupations); Q7: In a normal month, what is your total household income? which was recorded by grouping the income level reported in deciles of income within each country; Q13N: How many usable devices are there in the house? (smartphones, tablets or iPads, laptops, desktops), and Q14: How many computers per child have you got at home?

To measure the effect of families' digital access on parental involvement we include the predictor of technology at home, which corresponds to the following question, Q14: How many computers per child have you got at home ${ }^{2}$ This variable is added as a dummy variable in the model, where 0 means no computers all at home, and 1 represents either one per child or computer shared between parents and children at home.

On the other hand, we included a family structure variable, which was recorded as 0 for bi-parental households, and as 1 for single headed households. Additionally, include the variable of number of siblings in the household, which ranges from 0 to 10 . Finally, we consider the variable parental confidence using technology coded as 0 if parents are not confident and 1 if parents are confident in using technology.

\subsubsection{School Factors}

We incorporated a predictor of planned school activities and homework coded as 0 if the family does not receive a learning plan and 1 if the family receive a learning plan from the school. According to our research framework, this variable may be related to parental engagement.

\subsubsection{Child Factors}

For the analysis we use three variables related with child, i) child's gender $(0=$ Male or $1=$ Female $)$, ii $)$ child's age $(6-16$ years old $)$ and location $(0=$ Urban or $1=$ Rural $)$.

\subsection{Analytic Strategy}

We used analysis method Ordinary Least Square (OLS) regression with country (19 countries) fixed effects. OLS regression is a technique that uses a line to define the fit to the entire data set (Montgomery, et al., 2012). While the fixed effects regression model is represented in Eq. 1, the $\alpha_{i}$ are entity-specific intercepts that capture heterogeneity across entities (Hank et al., 2020). In this case, parental educational practices (dependent variable) vary by country. Therefore, to control for this variation, we incorporated a

${ }^{2}$ Since the variable Q14 regarding technology at home is included in the socioeconomic status scale (SES), we estimate different models for technology at home and SES. 
TABLE 3 | Descriptive statistics on parental involvement by country.

\begin{tabular}{|c|c|c|c|c|}
\hline \multirow[t]{2}{*}{ Countries } & \multicolumn{2}{|c|}{ Formal educational practices } & \multicolumn{2}{|c|}{ Informal educational practices } \\
\hline & Mean & Standard deviation & Mean & Standard deviation \\
\hline Chile & -0.0239 & 0.0715 & -0.0936 & 0.408 \\
\hline China & -0.0143 & 0.0615 & -0.1010 & 0.361 \\
\hline Colombia & -0.0145 & 0.0668 & -0.0909 & 0.427 \\
\hline Costa Rica & -0.0091 & 0.0590 & -0.0548 & 0.364 \\
\hline El Salvador & 0.0010 & 0.0497 & 0.0129 & 0.345 \\
\hline Ethiopia & 0.0163 & 0.0425 & 0.1280 & 0.352 \\
\hline Ghana & 0.0264 & 0.0395 & 0.2030 & 0.372 \\
\hline Honduras & -0.0054 & 0.0597 & -0.0126 & 0.392 \\
\hline India & 0.0184 & 0.0442 & 0.0496 & 0.353 \\
\hline Italy & -0.0107 & 0.0601 & -0.0535 & 0.366 \\
\hline Japan & -0.0018 & 0.0579 & 0.0570 & 0.355 \\
\hline Mexico & 0.0225 & 0.0473 & 0.2100 & 0.349 \\
\hline Pakistan & 0.0397 & 0.0244 & 0.2990 & 0.339 \\
\hline Sri Lanka & 0.0124 & 0.0521 & 0.1190 & 0.380 \\
\hline Tanzania & -0.0297 & 0.0767 & -0.0914 & 0.406 \\
\hline Turkey & 0.00580 & 0.0551 & 0.0567 & 0.336 \\
\hline United Kingdom & -0.0125 & 0.0630 & -0.0512 & 0.359 \\
\hline Uruguay & -0.0213 & 0.0712 & -0.0520 & 0.534 \\
\hline United States & -0.0053 & 0.0662 & 0.1080 & 0.369 \\
\hline
\end{tabular}

Source: ICIPES, 2020 (Osorio-Saez EM. et al., 2021).

dummy variable for each country, in line to other studies (Zhou, 2014; Gumus and Bellibas, 2016; Osorio-Saez E. et al., $2021)^{3}$. This strategy of adding fixed-effects by country allows for controlling variation due to differences across countries that may be due to unobserved variables. In addition, the SENWGT variable is included in the analysis, this factor "is a normalized (senate) weight variable that was created for analyses across a group of countries where contributions from each of the countries in the analysis was desired to be equal regardless of their population size" (Osorio-Saez et al., 2020: 20). This means that all countries contribute similarly to the coefficient, avoiding biases due to differences in sample size among countries.

$$
Y_{i c}=\beta_{0}+\beta_{1} X_{1, i c}+\ldots+\beta_{k} X_{k, i c}+\alpha_{c}+\varepsilon_{i c}
$$

Five models are fitted for each of the dependent variables. The first model includes only the fixed-effects by country. The second and third models estimate the relationship between formal educational practices or informal educational practices (dependent variable) and socioeconomic level (Model 2) or technology at home (Model 3) and school activities and homework, controlling for the effect of countries. Finally, the fourth and fifth model nests the previous two (second and third) but adds the characteristics of the child and the family, controlling for the country effect.

${ }^{3}$ Due to data limitations (sample size or not nested), low sample variability with respect to years of schooling per country, and the fact that we seek to control for cross-country variation in the independent variables, we use this technique (OLS regression with country fixed effect) instead of other analyses (e.g., multilevel models).

\section{FINDINGS}

The dimensions of parental involvement (formal and informal educational practices) by country show similar variations (Table 3). For such a reason, we decided to perform the analysis in 19 out of the 24 countries included in the ICIPES survey (Osorio-Saez EM. et al., 2021).

\subsection{Formal Educational Practices}

In relation to formal educational practices, socioeconomic level is a significant predictor $(\mathrm{B}=0.009, p<0.001)$, showing that families with a higher socioeconomic status provide more educational support to their children (Table 4). Although the coefficient is small this result is consistent with findings on the impact of the covid-19 pandemic on student learning due to socioeconomic status, for example. lower income students have fewer hours spent learning at home (Zancajo, 2020). In addition, parents who receive a learning plan or activities from the school tend to implement less formal educational practices $(\mathrm{B}=-0.004$, $p=0.05)$ than those who do not receive such material from the school. On the contrary, the availability of a computer at home for the child has a negative association with the implementation of formal educational practices.

Age, number of siblings, family structure and parents' confidence using technology are relevant predictors of formal educational practices. As the age of the child increases, parents provide less educational support $(\mathrm{B}=-0.001, p<0.001)$. Conversely, the more siblings in the household, the more formal educational practices parents engage in $(B=0.004, p<$ $0.001)$. This seems to be similar to teaching practices, which adapt to the age of the student recognizing evolving levels of autonomy from preschool to high school (Treviño, et al., 2019). On the other hand, parents who are confident in their capacity for the use of technology tend to provide more support to their children 
TABLE 4 | Regression model for formal educational practices.

\begin{tabular}{|c|c|c|c|c|c|}
\hline & Model 1 & Model 2 & Model 3 & Model 4 & Model 5 \\
\hline & $\begin{array}{c}\text { Formal educational } \\
\text { practices (with } \\
\text { dummy) }\end{array}$ & $\begin{array}{c}\text { Formal educational } \\
\text { practices (with } \\
\text { dummy) }\end{array}$ & $\begin{array}{c}\text { Formal educational } \\
\text { practices (with } \\
\text { dummy) }\end{array}$ & $\begin{array}{c}\text { Formal educational } \\
\text { practices (with } \\
\text { dummy) }\end{array}$ & $\begin{array}{c}\text { Formal educational } \\
\text { practices (with } \\
\text { dummy) }\end{array}$ \\
\hline Socioeconomic Status & - & $0.011(0.001)^{\star \star \star}$ & - & $0.009(0.001)^{\star \star \star}$ & - \\
\hline Technology at home & - & - & $-0.013(0.002)^{\star \star \star}$ & - & $-0.011(0.002)^{\star \star \star}$ \\
\hline Receives the learning plan & - & $-0.005(0.002)^{\star}$ & $-0.000(0.002)$ & $-0.004^{+}(0.002)$ & $-0.002(0.002)$ \\
\hline Female & - & - & - & $-0.003(0.002)$ & $-0.002(0.002)$ \\
\hline Rural & - & - & - & $-0.003(0.003)$ & $-0.001(0.003)$ \\
\hline Child age & - & - & - & $-0.001(0.000)^{\star \star \star}$ & $-0.001(0.000)^{\star \star \star}$ \\
\hline Children in the household & - & - & - & $0.004(0.001)^{\star \star \star}$ & $0.003(0.000)^{\star \star \star}$ \\
\hline Raising without a partner & - & - & - & $-0.005(0.003)$ & $-0.007(0.003)^{\star}$ \\
\hline Parental confidence & - & - & - & $0.018(0.003)^{\star \star \star}$ & $0.027(0.003)^{\star \star \star}$ \\
\hline Intercept & $0.001(0.001)$ & $0.004(0.002)^{*}$ & $0.012(0.002)^{\star \star \star}$ & $-0.011(0.004)^{\star \star}$ & $-0.013(0.004)^{\star \star \star}$ \\
\hline R-squared & 0.00 & 0.04 & 0.01 & 0.06 & 0.04 \\
\hline$N$ & 4,599 & 4.130 & 4,597 & 3.770 & 4.183 \\
\hline
\end{tabular}

Source: ICIPES, 2020. $+=0.05 .{ }^{*} p<0.05 .{ }^{* *} p<0.01 .{ }^{* * *} p<0.001$.

The analyses use Senate Weights (SENWT), in which the data for each country is expanded to the same population number nationally, ensuring that each country contributes equally to the estimation in this analysis that includes all the countries. Models include country fixed effects to control for differences across countries. Data on the table represents regression coefficients, and standard errors in parentheses, except for the last two lines which include the percentage of variance explained by the model and the total sample used for the estimations.

TABLE 5 | Regression model for informal educational practices.

\begin{tabular}{|c|c|c|c|c|c|}
\hline & Model 1 & Model 2 & Model 3 & Model 4 & Model 5 \\
\hline & $\begin{array}{l}\text { Informal educational } \\
\text { practices (with } \\
\text { dummy) }\end{array}$ & $\begin{array}{l}\text { Informal educational } \\
\text { practices (with } \\
\text { dummy) }\end{array}$ & $\begin{array}{l}\text { Informal educational } \\
\text { practices (with } \\
\text { dummy) }\end{array}$ & $\begin{array}{l}\text { Informal educational } \\
\text { practices (with } \\
\text { dummy) }\end{array}$ & $\begin{array}{c}\text { Informal educational } \\
\text { practices (with } \\
\text { dummy) }\end{array}$ \\
\hline Socioeconomic Status & - & $0.092(0.006)^{\star \star \star}$ & - & $0.086(0.006)^{\star \star \star}$ & - \\
\hline Technology at home & - & - & $-0.064(0.014)^{\star \star \star}$ & - & $-0.051(0.016)^{\star \star \star}$ \\
\hline Receives the learning plan & - & $-0.017(0.013)$ & $0.003(0.014)$ & $-0.016(0.015)$ & $-0.005(0.015)$ \\
\hline Female & - & - & - & $-0.024(0.012)^{\star}$ & $-0.022(0.012)$ \\
\hline Rural & - & - & - & $-0.020(0.017)$ & $-0.000(0.016)$ \\
\hline Child age & - & - & - & $-0.002(0.002)$ & $-0.003(0.002)$ \\
\hline Children in the household & - & - & - & $0.024(0.002)^{\star \star \star}$ & $0.024(0.003)^{\star \star \star}$ \\
\hline Raising without a partner & - & - & - & $-0.016(0.021)$ & $-0.028(0.020)$ \\
\hline Parental confidence & - & - & - & $0.078(0.022)^{\star \star \star}$ & $0.13(0.022)^{\star \star \star}$ \\
\hline Intercept & $0.040(0.006)^{\star \star \star}$ & $0.053(0.012)^{\star \star \star}$ & $0.091(0.015)^{\star \star \star}$ & $-0.042(0.023)$ & $-0.053(0.023)^{\star}$ \\
\hline R-squared & 0.01 & 0.07 & 0.01 & 0.08 & 0.04 \\
\hline$N$ & 4.599 & 4.130 & 4.597 & 3.770 & 4.183 \\
\hline
\end{tabular}

Source: ICIPES, 2020. *p $<0.05 .{ }^{* *} \mathrm{p}<0.01 .{ }^{* *} \mathrm{p}<0.001$

The analyses use Senate Weights (SENWT), in which the data for each country is expanded to the same population number nationally, ensuring that each country contributes equally to the estimation in this analysis that includes all the countries. Models include country fixed effects to control for differences across countries. Data on the table represents regression coefficients, and standard errors in parentheses, except for the last two lines which include the percentage of variance explained by the model and the total sample used for the estimations.

through formal educational practices $(\mathrm{B}=0.018, p<0.001)$, a finding consistent with the literature which suggests that availability of technology must be accompanied of knowledge on how to use the technology to support learning (Bol, 2020; 2021; Bayrakdar and Guveli, 2020; Bonal and Gonzalez, 2020). Finally, when considering the family structure (Model 5), it is found that parents who live alone with their children would have fewer formal educational practices $(\mathrm{B}=-0.007, p<0.05)$. The routine and division of labor in families changed during the COVID-19 lockdown (Larsen, et al., 2021), affecting the time spent on home schooling. This finding implies that single parents may resort to technological devices in the homeschooling process rather than formal educational practices due to lack of time. That is, factors at the individual and family level (besides SES) also affected parental involvement in home education (Horbny and Lafaele, 2011) during the school closures period.

\subsection{Informal Educational Practices}

Parental SES $(\mathrm{B}=0.086, p<0.001)$ and technology at home $(\mathrm{B}=$ $-0.051, p<0.001)$ are significant predictors of informal educational practices (Table 5). When controlling by SES the gender of the child becomes a significant predictor of informal practices $(\mathrm{B}=-0.024, p<0.05)$. That means that parents engage in informal practices with girls less frequently than they do with boys. This could be due to the fact that women and girls do most of the housework (IIEP-UNESCO, 2020). For example, girls aged 5-14 years already spend $40 \%$ more time doing household work than boys do, and girls between 5-9 years old spend 30\% more 
time on household chores than boys their age (UNICEF, 2016). This situation has increased (especially in less developed countries) in the COVID-19 pandemic and with the closure of schools (United Nations, 2020b). Therefore, this type of informal educational practices could be more common and independent (without parental support) for girls than for boys. On the other hand, the result on parents' confidence in their technological capabilities is maintained (Model 4: $\mathrm{B}=0.078, p<0.001$ and Model 5: $\mathrm{B}=0.13, p<0.001)$. In other words, the greater parental confidence the more informal educational activities they carry out with their children. This finding suggests that parental technological capabilities reinforce parental involvement in children's learning at home (Osorio-Saez E. et al., 2021).

\section{CONCLUSION}

This paper explores the main predictors of formal and informal parental practices at home in the context of the evidence showing a relationship between such practices and children's academic subjective well-being during the COVID-19 outbreak (e.g., Teso et al., 2020; Engel de Abreu et al., 2021; Larsen et al., 2021). Using an international database of 19 countries we analyzed the relationship between household SES and the type of parental practices. This section discusses our findings in light of previous literature and highlights our results' potentialities, limitations, and implications.

The main result of the article shows-without ignoring the limitations specified below-that SES is a significant predictor of parental involvement in formal and informal activities during the pandemic expansion. Although research has extensively discussed SES association with parental educational practices (e.g., Harris and Goodall, 2008; Lareau, 2000), the Covid outbreak and school closures introduce a new scenario in which inequalities in this respect are reproduced. While national studies in some middle and high-income countries have provided evidence of the critical role of family SES in the pandemic (Bonal and Gonzlez, 2020; Andrew et al., 2020; Bol, 2020), our findings shed light on common global patterns of parental involvement gaps by SES by using a large data of different 19 nations and controlling by country effects. The consistent and statistically significant gaps identified in formal and informal practices indicate a worldwide trend, which negatively affects disadvantaged children cross-nationally and may have a considerable impact on their academic achievement and subjective well-being. The socioeconomic inequalities in parental involvement uncovered might be rooted in the unique difficulties faced by low-SES parents due to the barriers they face in their material resources, economic hardships, and the time and energy constraints of their workload, as well as their relative lack of educational/pedagogical competencies and self-efficacy for helping their children in transferring learning activities from schools to their homes (e.g., Lareau, 2000; Horby and Lafaele, 2011; Wang et al., 2016).

Our results indicate that other factors, different from SES, are related to parental involvement. On the one hand, regarding family factors, our findings highlight the role of the household composition in parental engagement in home learning during the COVID-19 crisis. This finding is aligned with studies underlining the role of family structure in involvement both before the pandemic (Myers and Myers, 2015) and during its period (Bayrakdar and Guveli, 2020). In addition, parental confidence in technology is identified as a significant predictor of involvement in education, suggesting the crucial relationship of the ICT competencies of families in their participation in the schooling processes of their children in the period. This result is consistent with former evidence that has shown in some countries differences between parents already familiar vs unfamiliar with technology in learning at home (Bhamani et al., 2020) and the struggles faced by low-SES parents due to the lack of digital tools to support their children (Pozas et al., 2021). On the other hand, the age and gender of students (in the case of informal activities) are variables associated with families' engagement in home learning during the COVID-19 crisis, with involvement in formal activities decreasing as child age increases, and involvement being higher for boys in informal practices. The finding in terms of child age is consistent with former literature that has shown a decline in support and changes in parental strategies between elementary and middle/high school as students become more autonomous (Bhargava and Witherspoon, 2015; Wang and Sheikh-Khalil, 2014).

This paper has several limitations due to the fact that the study prioritized collecting data during school closures. First, similarly to other studies that took place during the COVID19 outbreak (e.g., Engel de Abreu et al., 2021), the use of a non-probabilistic sample limits the generalizations of the findings, despite their consistency with previous studies. Second, the use of internet and institutional social media may have caused a bias towards higher SES families having access to internet, underrepresenting families without this service (e.g., Engel de Abreu et al., 2021). Third, sample data shows that more than half of the sample of parents hold a higher education degree, a situation that suggests an upward bias in terms of SES. Fourth, this upward SES bias led us to recode formal parental practices to create dichotomous variables, instead of creating the index with all the Likert scale. This may reduce the true variance of practices and, also, reduces the variability of the practices' indexes. Fifth, although our models explain a limited proportion of the variance in formal and informal practices, the findings are consistent with previous studies. Sixth, parental involvement in formal educational practices presents low internal consistency, a result explained by upward bias of responses of families in the three practices that compose this indicator. This is also related to the bias towards higher SES families in the sample. Finally, the analysis for all countries (e.g., the sample size per country makes a comparative study difficult) limits the generalizability of the results, as the variables differ from country to country. The study results should be interpreted with these caveats in mind.

Without disregarding these limitations, our results introduce diverse policy implications aimed at supporting 
parents (especially those of lower SES) on their involvement in home learning in order to contribute to their children's academic achievement and subjective well-being. On the one hand, echoing international policy reports, our findings posit the urgency of generating strategies that assist parents in contributing to their children's educational experiences (e.g., OECD, 2020). Multiple alternatives have been proposed in this area, such as quality tutorials, teaching sessions, pedagogical material, child-oriented books, and enhancing school-family communication. On the other hand, our results point out the priority of investing in reversing the technological inequalities at home and improving families' digital competencies to promote their confidence using ICT. Finally, the role of child age and gender on parental involvement claims for tailored strategies that support parents through the children's different stages of development and combat the incipient gender gaps visualized.

\section{REFERENCES}

Andrew, A., Cattan, S., Costa Dias, M., Farquharson, C., Kraftman, L., Krutikova, S., et al. (2020). Inequalities in Children's Experiences of Home Learning during the COVID-19 Lockdown in England. Fisc Stud. 41 (3), 653-683. doi:10.1111/ 1475-5890.12240

Bayrakdar, S., and Guveli, A. (2020). "Inequalities In home Learning and Schools' Provision of Distance Teaching during School Closure of COVID-19 Lockdown in the UK. (No. 2020-09)," in ISER Working Paper Series (Colchester: University of Essex, Institute for Social and Economic Research ISER).

Bhamani, S., Makhdoom, A. Z., Bharuchi, V., Ali, N., Kaleem, S., and Ahmed, D. (2020). Home Learning in Times of COVID: Experiences of Parents. JoEED 7 (1), 9-26. doi:10.22555/joeed.v7i1.3260

Bhargava, S., and Witherspoon, D. P. (2015). Parental Involvement across Middle and High School: Exploring Contributions of Individual and Neighborhood Characteristics. J. Youth Adolesc. 44 (9), 1702-1719. doi:10.1007/s10964-0150334-9

Bhatia, R. (2020). Editorial: Effects of the COVID-19 Pandemic on Child and Adolescent Mental Health. Curr. Opin. Psychiatry 33 (6), 568-570. doi:10.1097/ YCO.0000000000000651

Bol, T. (2020). Inequality in Homeschooling during the Corona Crisis in the Netherlands. First Results from the LISS Panel. SocArXiv. doi:10.31235/osf.io/ hf $32 \mathrm{q}$

Bonal, X., and González, S. (2020). The Impact of Lockdown on the Learning gap: Family and School Divisions in Times of Crisis. Int. Rev. Educ. 66, 1-21. doi:10.1007/s11159-020-09860-Z

Brown, T. A. (2006). Confirmatory Factor Analysis for Applied Research. New York: The Guilford Press.

Castells, M. (2006). La Sociedad Red. Una Visión Global. Madrid, España: Alianza Editorial.

Engel de Abreu, P. M. J., Neumann, S., Wealer, C., Abreu, N., Coutinho Macedo, E., and Kirsch, C. (2021). Subjective Well-Being of Adolescents in Luxembourg, Germany, and Brazil during the COVID-19 Pandemic. J. Adolesc. Health 69 (2), 211-218. doi:10.1016/j.jadohealth.2021.04.028

Epstein, J. L. (2011). School, Family, and Community Partnership: Preparing Educators and Improving Schools. Philadelphia, PA: Westview Press.

Fontenelle-Tereshchuk, D. (2021). 'Homeschooling' and the COVID-19 Crisis: The Insights of Parents on Curriculum and Remote Learning. Interchange 52, 167-191. doi:10.1007/s10780-021-09420-w

Foster, R. C. (2021). KR20 and KR21 for Some Nondichotomous Data (It's Not Just Cronbach's Alpha). Educ. Psychol. Meas. 81 (0), 1172-1202. doi:10.1177/ 0013164421992535

Goodall, J., and Montgomery, C. (2014). Parental Involvement to Parental Engagement: A Continuum. Educ. Rev. 66 (4), 399-410. doi:10.1080/ 00131911.2013 .781576

\section{DATA AVAILABILITY STATEMENT}

The original contributions presented in the study are included in the article/Supplementary Material, further inquiries can be directed to the corresponding author.

\section{AUTHOR CONTRIBUTIONS}

All authors listed have made a substantial, direct, and intellectual contribution to the work and approved it for publication.

\section{FUNDING}

This work was funded by the Associative Research Program-ANID PIA CIE160007.

Goodall, J. (2013). Parental Engagement to Support Children's Learning: a Six point Model. Sch. Leadersh. Management 33 (2), 133-150. doi:10.1080/ 13632434.2012.724668

Gumus, E., and Bellibas, M. S. (2016). The Effects of Professional Development Activities on Principals' Perceived Instructional Leadership Practices: MultiCountry Data Analysis Using TALIS 2013. Educ. Stud. 42 (3), 287-301. doi:10.1080/03055698.2016.1172958

Hank, C., Arnold, M., Gerber, A., and Schmelzer, M. (2020). Introduction to Econometrics with R. Germany: University of Duisburg-Essen.

Harris, A., and Goodall, J. (2008). Do parents Know They Matter? Engaging All Parents in Learning. Educ. Res. 50 (3), 277-289. doi:10.1080/ 00131880802309424

Hornby, G., and Blackwell, I. (2018). Barriers to Parental Involvement in Education: An Update. Educ. Rev. 70 (1), 109-119. doi:10.1080/ 00131911.2018 .1388612

Hornby, G., and Lafaele, R. (2011). Barriers to Parental Involvement in Education: An Explanatory Model. Educ. Rev. 63 (1), 37-52. doi:10.1080/ 00131911.2010 .488049

IIEP-UNESCO (2020). COVID-19 School Closures: Why Girls Are More at Risk. Available at: http://www.iiep.unesco.org/en/covid-19-school-closures-whygirls-are-more-risk-13406 (Accessed September 27, 2021).

Lareau, A. (2000). Home Advantage. Social Class and Parental Intervention in Elementary Education. Maryland: Rowman \& Littlefield Publishers.

Lareau, A. (2011). Unequal Childhoods: Class, Race and Family Life. California: University California Press.

Larsen, L., Helland, M. S., and Holt, T. (2021). The Impact of School Closure and Social Isolation on Children in Vulnerable Families during COVID-19: a Focus on Children's Reactions. Eur. Child. Adolesc. Psychiatry 26 (1), 1-11. doi:10.1007/s00787-021-01758-x

Lavell, A., Mansilla, E., Maskrey, A. y., and Ramírez, F. (2020). The Social Construction of the COVID-19 Pandemic: Disaster, Risk Accumulation and Public Policy. Risk Nexus Initiative. Available at: http://desenredando.org

Ma, X., Shen, J., Krenn, H. Y., Hu, S., and Yuan, J. (2016). A Meta-Analysis of the Relationship between Learning Outcomes and Parental Involvement during Early Childhood Education and Early Elementary Education. Educ. Psychol. Rev. 28 (4), 771-801. doi:10.1007/s10648-015-9351-1

Mitra, R., Waygood, E. O. D., and Fullan, J. (2021). Subjective Well-Being of Canadian Children and Youth during the COVID-19 Pandemic: The Role of the Social and Physical Environment and Healthy Movement Behaviours. Prev. Med. Rep. 23 (4), 1014041-1014047. doi:10.1016/ j.pmedr.2021.101404

Montgomery, D. C., Peck, E. A., and Vining, G. G. (2012). Introduction to Linear Regression Analysis. 5th ed. New York: Wiley.

Myers, S. M., and Myers, C. B. (2015). Family Structure and School-Based Parental Involvement: A Family Resource Perspective. J. Fam. Econ. Iss 36 (1), 114-131. doi:10.1007/s10834-014-9409-0 
O'Connor, D. B., Aggleton, J. P., Chakrabarti, B., Cooper, C. L., Creswell, C., Dunsmuir, S., et al. (2020). Research Priorities for the COVID-19 Pandemic and beyond: A Call to Action for Psychological Science. Br. J. Psychol. 111 (4), 603-629. doi:10.1111/bjop.12468

OECD (2020a). OECD Policy Responses to Coronavirus (COVID-19): Combatting COVID-19's Effect on Children. Paris: OECD Publishing. doi:10.1787/ 2elf3b2f-en

OECD (2020b). "Combatting COVID-19's Effect on Children," in OECD Policy Responses to Coronavirus (COVID-19) (Paris: OECD Publishing).

Osorio-Saez, E., Eryilmaz, N., and Sandoval-Hernandez, A. (2021b). Parents' Acceptance of Educational Technology: Lessons from Around the World. Front. Psychol. 12, 1-17. doi:10.3389/fpsyg.2021.719430

Osorio-Saez, E. M., Eryilmaz, N., Sandoval-Hernandez, A., Lau, Y. Y., Barahona, E., Bhatti, A. A., et al. (2021a). Survey Data on the Impact of COVID-19 on Parental Engagement across 23 Countries. Data Brief 35 (1), 1-18. doi:10.1016/ j.dib.2021.106813

Osorio-Saez, E., Sandoval-Hernandez, A., Eryilmaz, N., and Kameshwara, K. K. (2020). ICIPES 2020 User Guide for the International Database. UK: University of Bath.

Parczewska, T. (2020). Difficult Situations and Ways of Coping with Them in the Experiences of Parents Homeschooling Their Children during the COVID-19 Pandemic in Poland. Education 3-13 49, 889-900. doi:10.1080/ 03004279.2020.1812689

Ponce Mancilla, T., Vielma Hurtado, C., and Bellei Carvacho, C. (2021). Experiencias educativas de niñas, niños y adolescentes chilenos confinados por la pandemia COVID-19. Rieoei 86 (1), 97-115. doi:10.35362/rie8614415

Pozas, M., Letzel, V., and Schneider, C. (2021). 'Homeschooling in Times of corona': Exploring Mexican and German Primary School Students' and Parents' Chances and Challenges during Homeschooling. Eur. J. Spec. Needs Education 36, 35-50. doi:10.1080/08856257.2021.1874152

Rajmil, L., Hjern, A., Boran, P., Gunnlaugsson, G., Kraus de Camargo, O., and Raman, S. (2021). Impact of Lockdown and School Closure on Children's Health and Well-Being during the First Wave of COVID-19: a Narrative Review. BMJ Paediatr. Open 5 (1), e001043-18. doi:10.1136/bmjpo-2021001043

Rogers, A., Castree, N. y., and Kitchin, R. (2013). Oxford Dictionary of Human Geography. Oxford: Oxford University Press.

Skwarchuk, S. L., Sowinski, C., and LeFevre, J. A. (2014). Formal and Informal home Learning Activities in Relation to Children's Early Numeracy and Literacy Skills: the Development of a home Numeracy Model. J. Exp. Child. Psychol. 121, 63-84. doi:10.1016/j.jecp.2013.11.006

Tan, C. Y., Lyu, M., and Peng, B. (2020). Academic Benefits from Parental Involvement Are Stratified by Parental Socioeconomic Status: A MetaAnalysis. Parenting 20 (4), 241-287. doi:10.1080/15295192.2019.1694836

Treviño, E., Miranda, C., Hernández, M., and Villalobos, C. (2021). Clase social y estrategias parentales de apoyo a los estudiantes en pandemia. Resultados para Chile del International COVID-19 Impact on Parental Engagement Study. Rieoei 86 (1), 117-133. doi:10.35362/rie8614449

Treviño, E., Varela, C., Rodríguez, M., and Straub, C. (2019). “Transformar las aulas en chile: superar la desconexión entre la enseñanza actual y los modos de aprender de los estudiantes," in De la reforma a la transformación. Capacidades, innovaciones y regulación de la educación chilena. Editors A. Carrasco, and L. Flores (Santiago, Chile: Ediciones UC), 173-216.

Tso, W. W. Y., Wong, R. S., Tung, K. T. S., Rao, N., Fu, K. W., Yam, J. C. S., et al. (2020). Vulnerability and Resilience in Children during the COVID-19 Pandemic. Eur. Child. Adolesc. Psychiatry, 1-16. doi:10.1007/s00787-02001680-8
Unicef (2021). Covid-19 and School Closures. Available at: https://data.unicef.org/ resources/one-year-of-covid-19-and-school-closures/(Accessed August 10, 2021).

Unicef (2016). Girls Spend 160 Million More Hours Than Boys Doing Household Chores Everyday. Available at: https://www.unicef.org/pressreleases/ girls-spend-160-million-more-hoursboys-doing-household-chores-everyday (Accessed September 27, 2021).

United Nations (2020a). Policy Brief: Education during COVID-19 and beyond. Available at: https://unsdg.un.org/es/resources/informe-de-politicaseducacion-durante-covid-19-y-mas-alla (Accessed 09 August, 2021).

United Nations (2020b). Policy Brief: The Impact of COVID-19 on Women. Available at: https://asiapacific.unwomen.org/en/digital-library/publications/2020/04/policybrief-the-impact-of-covid-19-on-women (Accessed August 16, 2021).

Van Voorhis, F. L., Maier, M. F., Epstein, J. L., and Lloyd, C. M. (2013). The Impact of Family Involvement on the Education of Children Ages 3 to 10: A Focus on Literacy and Math Achievement Outcomes and Social-Emotional Outcomes. New York, MD: MDRC.

Viner, R., Russell, S., Saulle, R., Croker, H., Stansfeld, C., Packer, J., et al. (2021). Impacts of School Closures on Physical and Mental Health of Children and Young People: A Systematic Review. MedRxiv preprint. Available at: https:// www.medrxiv.org/content/10.1101/2021.02.10.21251526v1. doi:10.1101/ 2021.02.10.21251526

Wang, M. T., and Sheikh-Khalil, S. (2014). Does Parental Involvement Matter for Student Achievement and Mental Health in High School? Child. Dev. 85 (2), 610-625. doi:10.1111/cdev.12153

Wang, Y., Deng, C., and Yang, X. (2016). Family Economic Status and Parental Involvement: Influences of Parental Expectation and Perceived Barriers. Sch. Psychol. Int. 37 (5), 536-553. doi:10.1177/0143034316667646

Wilder, S. (2014). Effects of Parental Involvement on Academic Achievement: a Meta-Synthesis. Educ. Rev. 66 (3), 377-397. doi:10.1080/00131911.2013.780009

Zancajo, A. (2020). The Impact of the Covid-19 Pandemic on Education: Rapid Review of the Literature Covid and Society-British Academy. The British Academy [Preprint]. Available at: https://www.thebritishacademy.ac.uk/ publications/covid-decade-impact-of-the-pandemic-on-education/(Accessed August 09, 2021).

Zhou, Y. (2014). The Relationship between School Organizational Characteristics and Reliance on Out-Of-Field Teachers in Mathematics and Science: CrossNational Evidence from TALIS 2008. Asia-pacific Edu Res. 23 (3), 483-497. doi:10.1007/s40299-013-0123-8

Conflict of Interest: The authors declare that the research was conducted in the absence of any commercial or financial relationships that could be construed as a potential conflict of interest.

Publisher's Note: All claims expressed in this article are solely those of the authors and do not necessarily represent those of their affiliated organizations, or those of the publisher, the editors and the reviewers. Any product that may be evaluated in this article, or claim that may be made by its manufacturer, is not guaranteed or endorsed by the publisher.

Copyright (๑) 2021 Treviño, Miranda, Hernández and Villalobos. This is an openaccess article distributed under the terms of the Creative Commons Attribution License (CC BY). The use, distribution or reproduction in other forums is permitted, provided the original author(s) and the copyright owner(s) are credited and that the original publication in this journal is cited, in accordance with accepted academic practice. No use, distribution or reproduction is permitted which does not comply with these terms. 